\title{
POTENSI LEMPUNG DAN FELSPAR UNTUK BAHAN BAKU KERAMIK DI DAERAH PURWANEGARA, KABUPATEN BANJARNEGARA, JAWA TENGAH
}

Oleh:

\author{
Penny Oktaviani dan Irwan Muksin \\ Pusat Sumber Daya Geologi \\ Jalan Soekarno-Hatta No.444, Badung
}

\section{SARI}

Ketersediaan bahan baku merupakan salah satu faktor penting untuk kelangsungan hidup industri keramik. Salah satunya yang berada di Daerah Klampok, Kecamatan Purwareja, Kabupaten Banjarnegara. Di daerah ini pada umumnya industri keramik merupakan industri kecil dan menengah. Kajian ini dilakukan dengan maksud untuk menginventarisasi lokasi lempung dan felspar yang dapat dijadikan bahan baku pembuatan keramik di sekitar lokasi sentra industri Klampok, karena selama ini bahan baku diambil dari luar Banjarnegara, bahkan hingga mendatangkan bahan baku dari Pulau Belitung, Sumatera. Tujuannya agar para pengrajin memiliki alternatif lokasi pengambilan bahan baku dari sekitar lokasi industri untuk mengurangi biaya produksi demi kelangsungan industri mereka.

Berdasarkan evaluasi data lapangan dan hasil analisis laboratorium, baik kimia, fisika dan uji prototype benda keramik, lempung dan felspar di 3 lokasi yang diamati, yaitu felspar di Dukuh Kretek dan Desa Kalitengah, serta lempung di Kampung Penisian, Desa Merden, Kecamatan Purwanegara terbukti dapat dijadikan sebagai lokasi alternatif bahan baku untuk pembuatan keramik.

Conto lempung dan felspar dari ketiga lokasi tersebut secara tunggal dapat digunakan sebagai bahan untuk pembuatan gerabah dengan pembakaran suhu rendah $\left(<1.000^{\circ} \mathrm{C}\right)$. Dan apabila dua conto dicampur dengan komposisi tertentu, maka dapat dibuat untuk keramik dengan kualitas yang lebih baik dari gerabah, yaitu keramik hias atau table wares.

Kata kunci: felspar, industri keramik, lempung

\section{ABSTRACT}

Raw material supply is one of the important factor for ceramic industry to survive. One of these industries located at Klampok area, Purwareja district, Banjarnegara regency. At this area,ceramic industries are mainly small and medium industries. This study is to inventarize clay and feldspar location that suitable for ceramic raw material around Klampok area, because up to now raw material come from area outside Banjarnegara, some of it come from Belitung area in Sumatera Island. The objective of this study is to give some alternative locations of raw material for the craftsman, closed to their industry to minimize production cost for their business efficiency and continuity.

Based on field data evaluation and laboratory analysis result, clay and feldspar in 3 observed locations; feldspar at Dukuh Kretek and Kalitengah Village, and clay at Kampung Penisian, Merden Village, Purwanegara District can be use as ceramic raw material location.

Clay and feldspar sample from those three locations can be used to make earthen ware material with low burning temperature $\left(<1000^{\circ} \mathrm{C}\right)$. And if two of those samples are mixed together with certain composition, it can be used to make a better quality product than earthenwares, which is called ceramics or table wares.

Keywords: feldspar, ceramic industry, clay

\section{PENDAHULUAN}

Berdasarkan Instruksi Presiden Republik Indonesia nomor 6 Tahun 2009 tentang pengembangan ekonomi kreatif, dalam rangka keterpaduan pelaksanaan pengembangan ekonomi kreatif, Kementerian Energi dan Sumber Daya Mineral (ESDM) turut serta mendukung dan melaksanakan kebijakan pengembangan ekonomi kreatif tahun 2009 - 2012, yaitu dengan melakukan pengembangan kegiatan 
ekonomi berdasarkan pada kreativitas, keterampilan dan bakat individu yang bernilai ekonomis dan berpengaruh pada kesejahteraan masyarakat Indonesia.

Industri kreatif ini telah mampu memberikan sumbangan kepada PDB nasional secara signifikan yaitu dengan ratarata kontribusi periode 2002 - 2006 sebesar 104,637 triliun rupiah atau dengan rata-rata persentase kontribusi periode 2002 - 2006 sebesar $6,28 \%$. Pada tahun 2006 , kontribusi PDB Industri Kreatif berdasarkan harga konstan 2000 adalah sebesar 104,787 triliun rupiah yaitu $5,67 \%$ dari total PDB Nasional. Jika dihitung dengan nilai nominal senilai 189,4 triliun rupiah (Pangestu, 2008).

Salah satu subsektor Industri kreatif adalah kerajinan menyumbang sekitar 26,7 triliun rupiah atau sebesar $25,51 \%$ (Pangestu, 2008), yang di dalamnya ada industri kerajinan keramik. Industri kerajinan keramik merupakan salah satu industri berbasis ekonomi kreatif yang terdapat di alternatif penggunaan bahan baku di sentra keramik Klampok, Kecamatan Purwanegara, Kabupaten Banjarnegara, Provinsi Jawa Tengah (Gambar 1), yang merupakan hasil satu kajian yang pernah dilakukan di PSDG (2012) dalam rangka membantu para pengrajin sentra keramik di daerah Jawa Barat, Jawa Tengah dan Yogyakarta untuk memenuhi kebutuhan bahan bakunya. Kajian dilakukan dengan melakukan inventarisasi lokasi lempung dan felspar yang dapat dijadikan bahan baku pembuatan keramik di sekitar lokasi sentra industri keramik, tujuannya agar para pengrajin memiliki alternatif lokasi pengambilan bahan baku dari sekitar lokasi industri dan mengurangi biaya produksi industri mereka.

Pada umumnya industri keramik merupakan industri kecil dan menengah, mengambil bahan baku dari sekitar lokasi industri. Lain halnya dengan sentra keramik Klampok, selama ini para pengrajin di

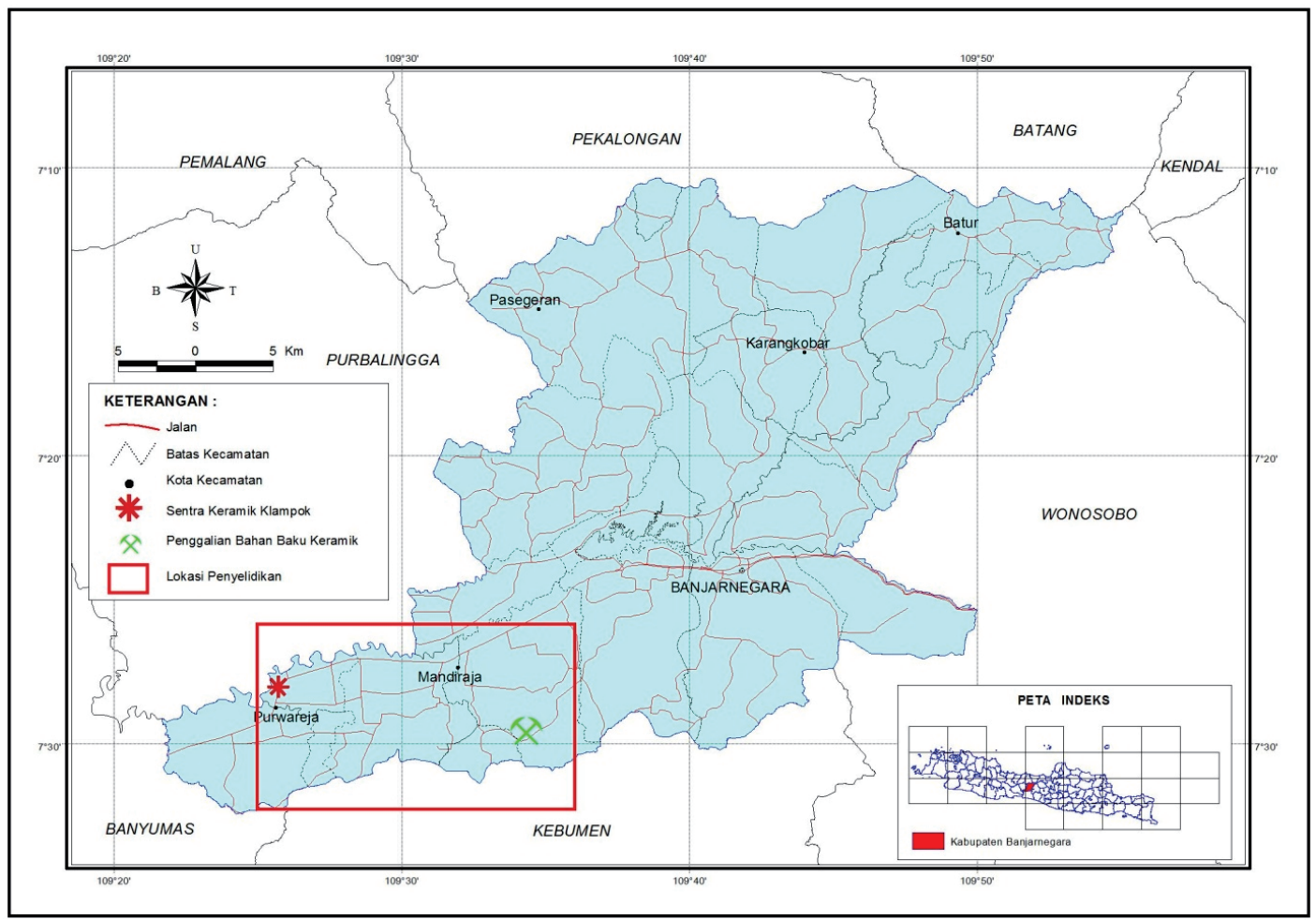

Gambar 1. Lokasi kegiatan di Kabupaten Banjarnegara, Provinsi Jawa Tengah.

beberapa tempat di Pulau Jawa, diantaranya sentra keramik Plered di Kabupaten Purwakarta, Klampok di Kabupaten Banjarnegara, Melikan di Kabupaten Klaten, Pundong dan Kasongan di Kabupaten Bantul.

Tulisan ini membahas mengenai
Klampok mengambil bahan baku dari luar Banjarnegara, bahkan hingga mendatangkan bahan baku dari Pulau Belitung, Sumatera, sehingga kontuinatas produksi terganggu dan mengurangi efisiensi industri keramik tersebut.

Di Sentra Keramik Klampok, 
Kabupaten Banjarnegara, Jawa Tengah terdapat terdapat 20 pengrajin, 2 pengrajin mempunyai nama dagang dan sisanya merupakan pengrajin biasa (home industry). Umumnya jenis keramik yang dihasilkan berupa gerabah keramik fungsi, keramik hias, keramik tradisional, keramik cinderamata dengan tungku bahan bakar kayu (Gambar 2). Sedangkan yang sudah memiliki merek dagang, selain gerabah, juga memproduksi jenis porselen (stoneware) (Gambar 3) dan sudah menggunakan tungku bahan bakar gas LPG. Pembakaran menggunakan gas LPG lebih baik karena panas yang dihasilkan lebih merata dibandingkan menggunakan kayu
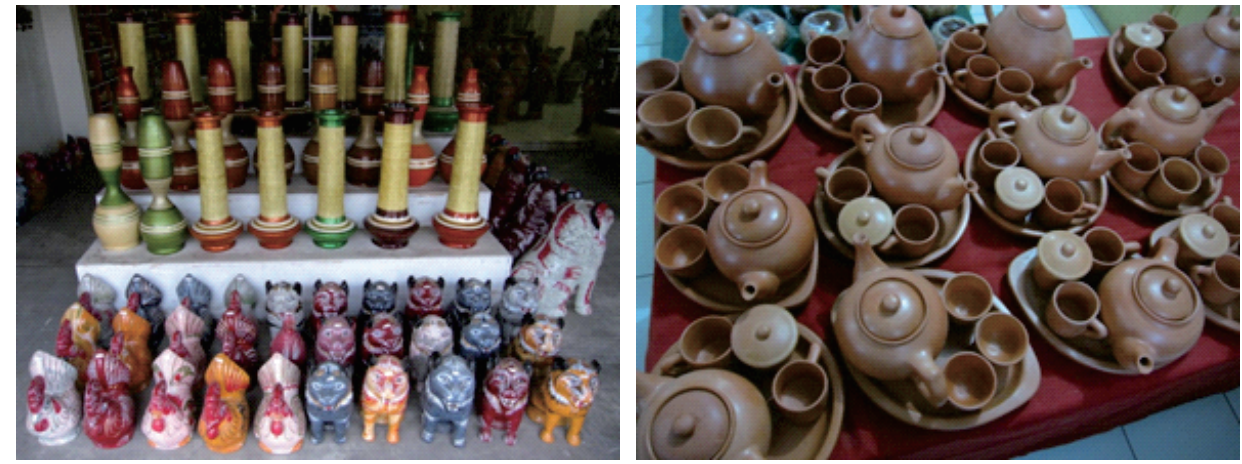

Gambar 2. Beberapa produk gerabah dari Sentra Keramik Klampok, Kabupaten Banjarnegara, Jawa Tengah (kiri); Produk khas yang dipesan oleh hotel dan restoran (kanan).

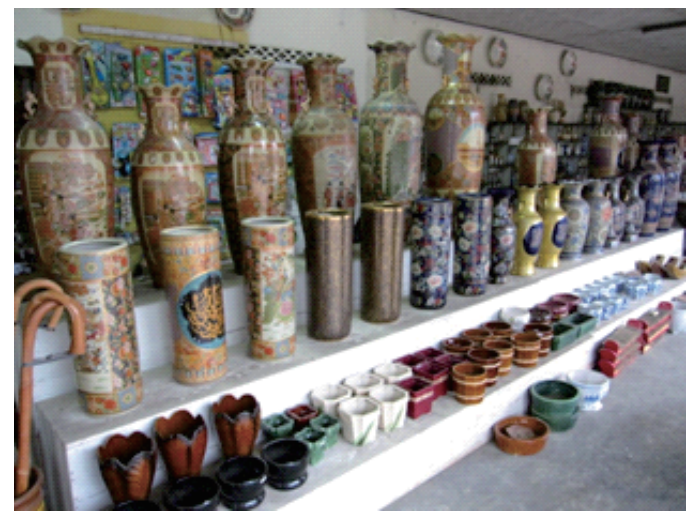

Gambar 3. Beberapa produk jenis porselen (stoneware) dari Sentra keramik Klampok, Kabupaten Banjarnegara, Jawa Tengah.

bakar, suhu panas yang dihasilkan juga bisa lebih tinggi sehingga kualitas produknya lebih baik.

\section{METODE KAJIAN}

Kegiatan kajian mencakup tahap persiapan, pengumpulan data primer ke lapangan, analisis laboratorium, dan pengolahan data.
Tahap persiapan meliputi pengadaan peta geologi skala $1: 100.000$, peta topografi, dan pengumpulan data sekunder mengenai sentra kerajinan keramik.

meliputi:

Tahap pengumpulan data primer

- Pendataan di Sentra Gerabah Klampok, Desa Klampok, Kecamatan Purwareja, Kabupaten Banjarnegara.

- Pengambilan perconto lempung di daerah Kecamatan Purwanegara, Kabupaten Banjarnegara untuk dianalisis fisika/kimia di laboratorium.

- Evaluasi dan analisis sementara di lapangan.

Tahap analisis Laboratorium meliputi 
pengujian data hasil pengamatan lapangan dan analisis laboratorium.

\section{GEOLOGI DAN BAHAN BAKU KERAMIK DI DAERAH PURWANEGARA}

Menurut Peta Geologi Lembar Banjarnegara dan Pekalongan, Jawa skala 1 : 100.000 (Condon,W.H., dkk., 1996), daerah ini secara berurutan dari tua ke muda disusun oleh (Gambar 4):

Komplek Lok Ulo (KTI); merupakan bancuh terdiri dari berbagai bongkahan yang tercampur secara tektonik dalam matrik serpih dan batulanau kelabu gelap yang terkoyakkan. Ukuran bongkah tak seragam dan tersusun oleh basal, rijang hitam, merah, batuan basa dan ultrabasa (Kog), sekis dan filit $(\mathrm{Km})$, grewak (KTs), granit, tuf terkersikkan, batugamping merah dan kelabu serta lempung. Umumnya bongkahan berbentuk lonjong, setiap batas litologi merupakan sentuh tektonik. Rijang terlipatkan kuat, berselingan dengan batulempung merah.

Formasi Totogan (Tomt); terdiri dari breksi, batulempung, napal, konglomerat, dan batupasir. Batulempung tufaan berinterkalasi dengan breksi.

Anggota Tuf Formasi Waturanda (Tmwt); terdiri dari perselingan tuf kaca, tuf hablur, batupasir gampingan dan tuf napalan.

Formasi Waturanda (Tmw); terdiri dari breksi, batupasir, konglomerat, lahar dengan sisipan batulempung.

Formasi Penosogan (Tmp); terdiri perselingan konglomerat, batupasir, batulempung, napal, tuf dan riolit. Perselingan batulempung, napal, dan kalkarenit dan tuf menempati bagian tengah sekuen.

Formasi Halang (Tmph); bagian atas terdiri dari breksi gunungapi yang bersifat andesit dan basal, bagian bawah terdiri dari batupasir, tuf, batulempung, konglomerat, batupasir merupakan bagian utama.

Anggota Breksi, Formasi Ligung (QTIb); terdiri dari breksi gunungapi yang bersifat andesit, lava andesit dan tuf, merupakan bagian atas Formasi Ligung.

Endapan Undak (Qt); terdiri pasir, lanau, tuf, konglomerat, batupasir tufaan dan breksi tufaan. Tersebar di sepanjang Lembah Serayu.

Aluvial (Qa); kerikil, pasir, lanau dan lempung, sebagai endapan sungai.

Endapan feldspar selama ini dijumpai dan ditambang dari satuan grewak (Kts) dalam Komplek Lok Ulo berupa bongkahan bongkahan besar, sedangkan lempung juga dijumpai pada komplek ini dalam bentuk bongkahan-bongkahan.

Melihat litologi yang ada pada formasi lainnya di daerah Purwanegara dan sekitarnya, kemungkinan feldspar dapat dijumpai berupa tuf kaca dan tuf hablur dari Anggota Tuf Formasi Waturanda dan tuf serta riolit dari Formasi Penosogan.

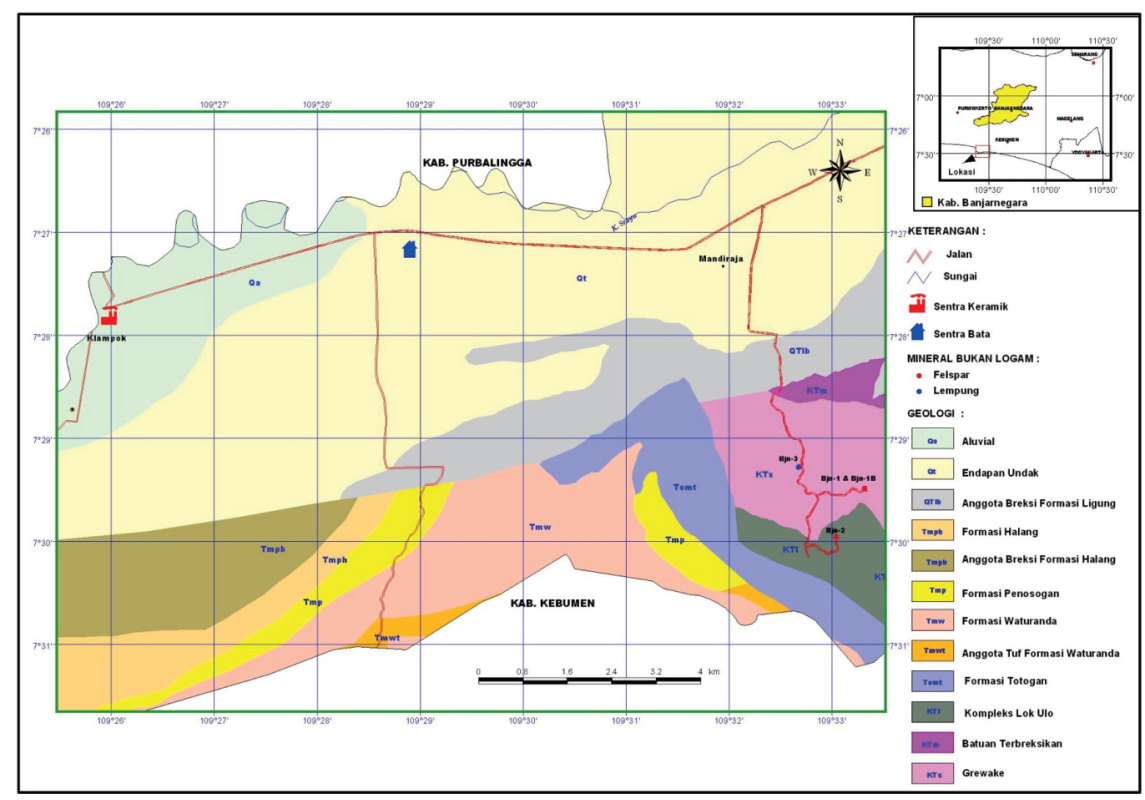

Gambar 4. Peta geologi daerah Purwanegara dan sekitarnya, Kabupaten Banjarnegara. 
Endapan lempung selain berupa bongkahan-bongkahan pada Komplek Lok Ulo, kemungkinan dijumpai berupa satuan batuan dari Formasi Totogan dan Penosogan, yang sudah dimanfaatkan sebagai bahan pembuatan bata adalah lempung dari satuan Undak Sungai. Perlu dilakukan eksplorasi lanjutan pada bahan baku keramik di daerah ini.

\section{HASIL DAN ANALISIS}

Pengamatan endapan felspar dan lempung dilakukan terhadap 2 lokasi endapan felspar, dan 1 lokasi endapan lempung. Endapan felspar di Dukuh Kretek, Desa Kalitengah, Kecamatan Purwanegara (Bjn-1) dan di Desa Kalitengah, Kecamatan Purwanegara (Bjn-2). Endapan lempung berada di Kampung Penisian, Desa Merden, Kecamatan Purwanegara (Bjn-3).

Endapan felspar di Dukuh Kretek, Desa Kalitengah, Kecamatan Purwanegara (Gambar 5) dijumpai dalam kondisi lapuk, berwarna coklat kekuningan (krem), rapuhkeras, membentuk bukit, ditumbuhi tanaman keras, pernah diusahakan oleh penduduk, dikirim ke industri keramik di Jakarta. Terdapat pada satuan grewak Satuan Tektonik Komplek Lok Ulo.

Endapan felspar di Desa Kalitengah, Kecamatan Purwanegara (Gambar 6), lapuk, berwarna putih coklat kekuningan (krem), membentuk bukit, sebarannya membentuk bongkah-bongkah berukuran $5 \times 5 \mathrm{~m}$, diusahakan oleh penduduk, dikirim ke industri keramik di Jakarta. Terdapat pada satuan grewak Satuan Tektonik Komplek Lok Ulo.

Endapan lempung di Kampung Penisian, Desa Merden, Kecamatan Purwanegara (Gambar 7), berwarna hitam (scally clay?), keras, plastis jika kena air, dijumpai berupa bongkahan dengan ukuran $20 \times 5 \mathrm{~m}$. Dari hasil analisa XRD conto lempung, mengandung kuarsa, mika, albit dan muskovit. Terdapat pada satuan grewak Satuan Tektonik Komplek Lok Ulo.

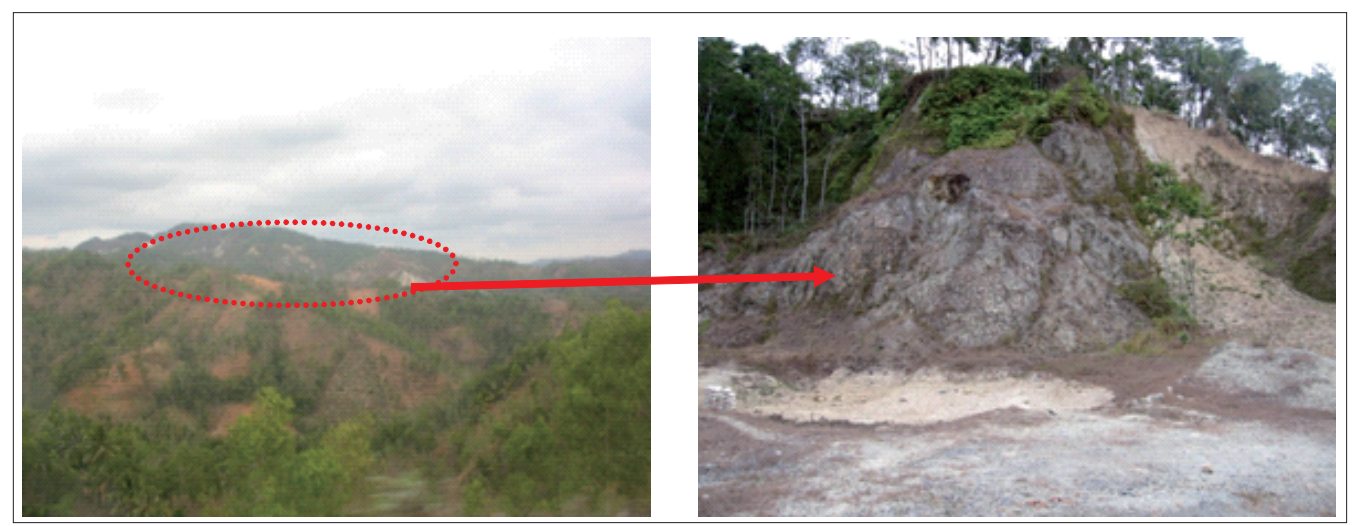

Gambar 5. Kenampakan sebaran dan singkapan endapan felspar di daerah Kalitengah, Kecamatan Purwanegara

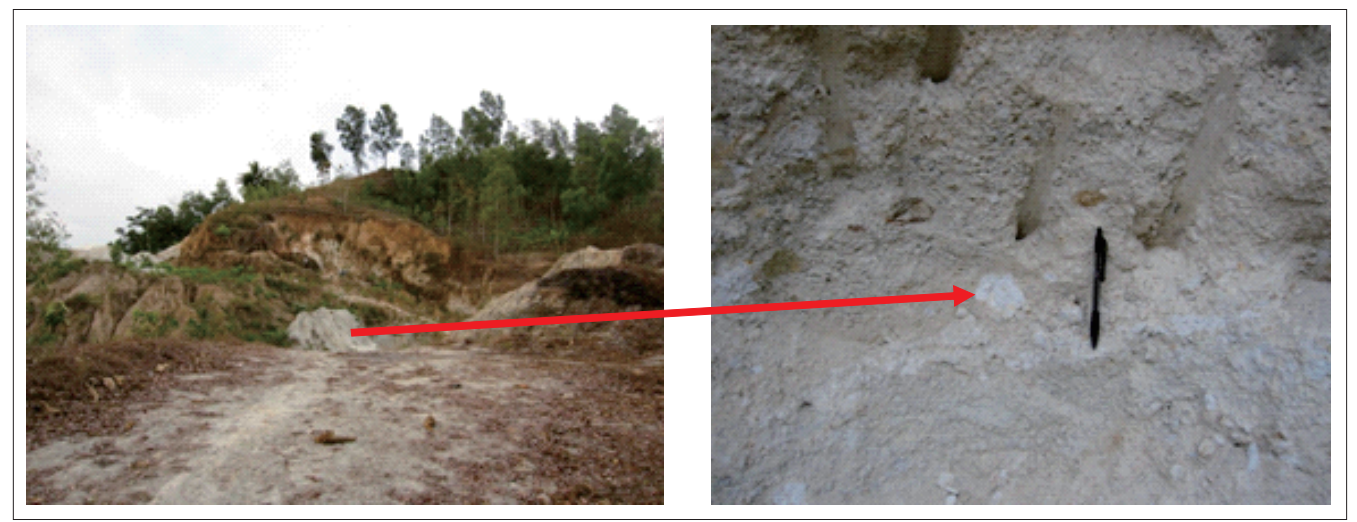

Gambar 6. Singkapan felspar di daerah Kalitengah, Kecamatan Purwanegara, merupakan bongkahan grewak dari Satuan Tektonik Komplek Lok Ulo. 

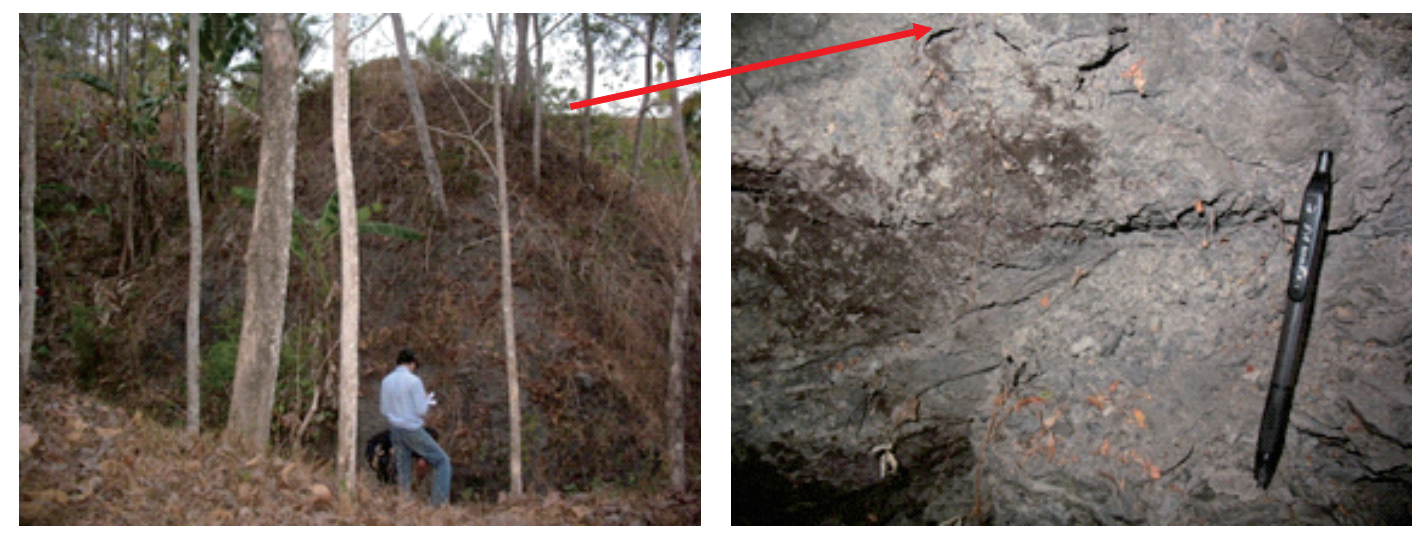

Gambar 7. Singkapan endapan lempung dari Satuan Tektonik Komplek Lok Ulo berupa bongkah berukuran $20 \times 5 \mathrm{~m}$.

Endapan feldspar di daerah Dukuh Kretek, Desa Kalitengah, Kecamatan Purwanegara, mempunyai luas sebaran \pm 5 ha, dengan ketebalan rata-rata $3 \mathrm{~m}$, sumberdaya hipotetiknya $150.000 \mathrm{~m}^{3}$, endapan feldspar di daerah Desa Kalitengah, Kecamatan Purwanegara, mempunyai luas sebaran \pm 10 ha, dengan ketebalan rata-rata $3 \mathrm{~m}$, sumberdaya hipotetiknya $300.000 \mathrm{~m}^{3}$, sedangkan endapan lempung di Kampung Penisian, Desa Merden, Kecamatan Purwanegara dijumpai berupa bongkahan dengan ukuran $20 \times 5 \mathrm{~m}$, dengan ketebalan $3 \mathrm{~m}$, sumberdaya hipotetiknya $300 \mathrm{~m}^{3}$.

Endapan felspar di Dukuh Kretek, dari dua conto yang dianalisa kimia (Bjn-1a dan Bjn-1b) diketahui mengandung 16,33$17,61 \% \quad \mathrm{Al}_{2} \mathrm{O}_{3}, 67,49-67,60 \% \quad \mathrm{SiO}_{2}, 4,16-$ $8,58 \% \mathrm{~K}_{2} \mathrm{O}$, dan $0,60-0,64 \% \mathrm{Na}_{2} \mathrm{O}$. Endapan felspar di Desa Kalitengah (Bjn-2) memiliki kandungan $\mathrm{Al}_{2} \mathrm{O}_{3}: 16,16 \%, \mathrm{SiO}_{2}: 73,03 \%$, $\mathrm{K}_{2} \mathrm{O}: 6,37 \%$, dan $\mathrm{Na}_{2} \mathrm{O}: 0,00 \%$.

Endapan lempung di Kampung Penisian memiliki kandungan $\mathrm{Al}_{2} \mathrm{O}_{3}: 18,31 \%$, $\mathrm{SiO}_{2}: 61,91 \%, \mathrm{CaO} ; 0,43 \%$, dan $\mathrm{MgO}$ : $2,21 \%$.
Persentase kandungan $\mathrm{Al}_{2} \mathrm{O}_{3}, \mathrm{SiO}_{2}$, $\mathrm{K}_{2} \mathrm{O}, \mathrm{Na}_{2} \mathrm{O}, \mathrm{CaO}$, dan $\mathrm{MgO}$ memenuhi persyaratan sebagai bahan baku keramik.

Uji bakar dilakukan terhadap 4 conto untuk mengetahui sifat-sifat dasar bahan baku keramik, yaitu Bjn-1 dan Bjn-1B merupakan conto endapan felspar di Dukuh Kretek, Desa Kalitengah, Kecamatan Purwanegara, Bjn-2 merupakan conto endapan felspar di Desa Kalitengah, Kecamatan Purwanegara, dan Bjn-3 merupakan conto endapan lempung di Kampung Penisian, Desa Merden, Kecamatan Purwanegara.

Dari hasil uji sifat-sifat dasar bahan baku keramik, 2 conto felspar (Bjn-1 dan Bjn1B) kemungkinan dapat digunakan sebagai bahan tunggal untuk body earthenware (gerabah) dengan pembakaran suhu rendah $\left(<1.000^{\circ} \mathrm{C}\right)$. Untuk felspar Bjn-2 kemungkinan dapat digunakan sebagai body stoneware. Untuk conto lempung Bjn-3 kemungkinan dapat digunakan sebagai bahan tunggal untuk body earthenware dengan pembakaran suhu rendah (Gambar 8).

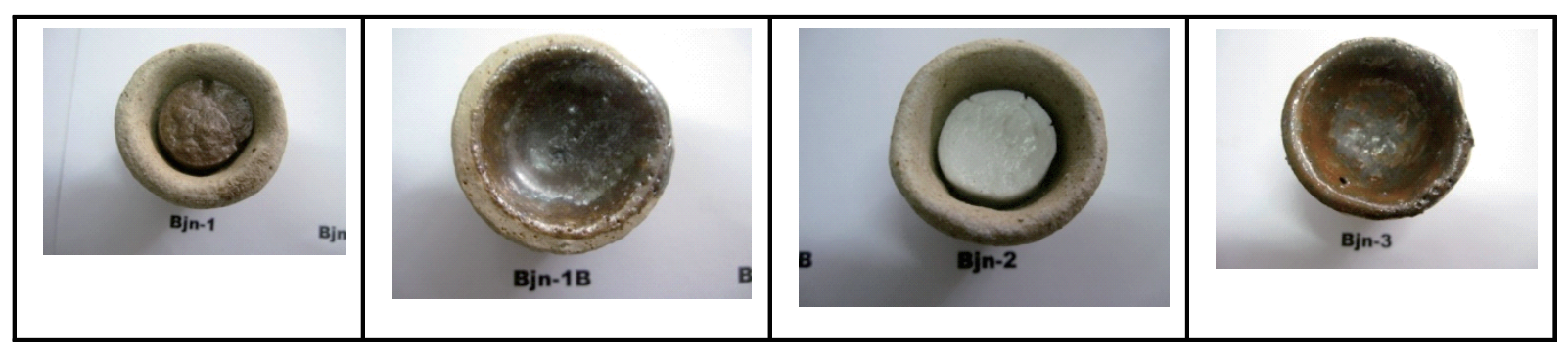

Gambar 8. Hasil Uji Bakar PS-14 Bahan tunggal Daerah Purwanegara. 


\section{MAKALAH ILMIAH}

Untuk meningkatkan kualitas keramik dari jenis gerabah ke jenis stoneware (keramik) yang mempunyai nilai jual lebih tinggi, dilakukan uji coba komposisi campuran lempung dan felspar, merupakan campuran lempung daerah Kampung Penisian, Desa Merden, Kabupaten Banjarnegara (Bjn-3) dan felspar daerah Desa Kalitengah, Kecamatan Purwanegara, Kabupaten Banjarnegara (Bjn-2).

Dari hasil uji coba pendahuluan komposisi di atas, hasilnya adalah sebagai berikut (Gambar 9) :

- Pori-pori : sedikit sekali

- Massa gelas : sempurna

- Gelembung : sedikit sekali

- Homogenitas Leburan : merata

- Homogenitas warna : merata

- Warna Sebelum dibakar: Abu-abu

- Warna Setelah dibakar: Coklat

- Keplastisan Atterberg: Agak Plastis

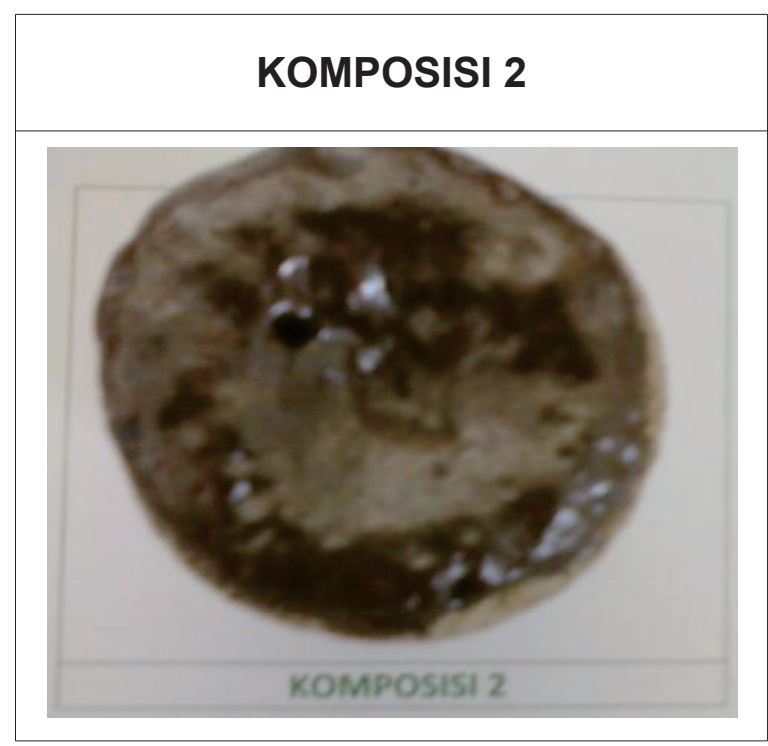

Gambar 9. Hasil Uji Bakar PS-14 Komposisi.

Dari hasil uji coba teknologi, hasil bakar pada temperatur $900^{\circ} \mathrm{C}$ untuk membuat Benda Uji (Gambar 10) menunjukan susut kering 3,58 \%, berwarna kering abu-abu. Susut bakar $-0,51 \%$ (mengembang), susut jumlah 3,09\%, penyerapan air 15,69\%m berwarna bakar krem, dan kepekaan terhadap pengeringan (Dse) 4,15 (sangat peka).

Selanjutnya uji coba benda keramik pada tahap Prototype, dilakukan dengan cara pengaturan komposisi, pembuatan prototype (keramik hias), pembakaran suhu $1.100^{\circ} \mathrm{C}$, dan pengujian prototype (susut dan peresapan air) sehingga hasil uji coba adalah sebagai berikut (Gambar 11).

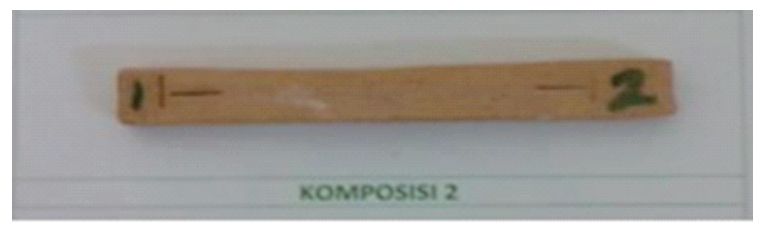

Gambar 10. Hasil Uji Bakar Benda Uji.

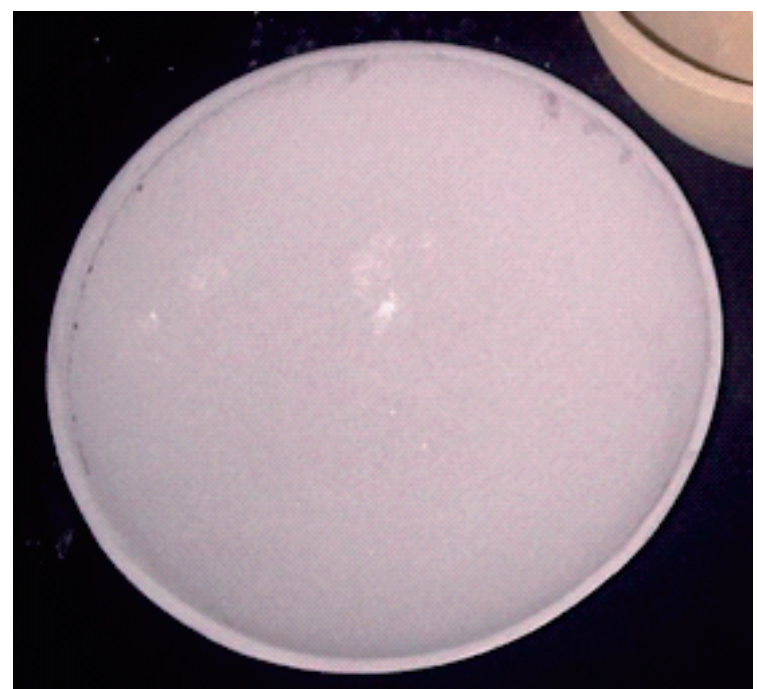

Gambar 11. Hasil Uji Bakar Prototipe Komposisi lempung, feldspar serta aditif

Dari hasil analisis uji prototype benda keramik, diketahui bahwa bahan tunggal lempung dari daerah yang diamati kemungkinan dapat digunakan sebagai bahan tunggal untuk gerabah (body earthenware) dengan pembakaran suhu rendah dan komposisi felspar dari satuan grewaki pada Komplek Lok Ulo dan lempung pada komplek yang sama dapat dibuat untuk keramik hias (table wares) dengan campuran kaolin sebanyak $30 \%$, penambahan aditif water glass dan dextrin sebanyak < 5\%, dan dengan teknik pembentukan cara cor (slip casting) pada suhu pembakaran $1.100^{\circ} \mathrm{C}$.

\section{KESIMPULAN DAN SARAN}

Dari Hasil penelitian lapangan dan laboratorium diketahui bawha lembpung di daerah penelitian dapat digunakan sebagai bahan tunggal untuk gerabah dengan pembakaran suhu rendah $\left(<1.100^{\circ} \mathrm{C}\right)$. Felspar dari satuan batuan grewak dan 
lempung dari Komplek Lok Ulo dapat dibuat menjadi keramik hias.

Untuk itu disarankan melakukan :

a. Penambangan yang mengikuti kaidah-kaidah yang benar (good mining practices), khususnya dalam lineasi potensi feldspar dan lempung, sehingga kualitas dan mutu bahan baku terjaga.

b. Perlu adanya peta potensi sumberdaya lempung dan fedspar, sehingga pengrajin dapat mencari bahan baku keramik di wilayah sekitarnya.

c. Prospeksi dan eksplorasi untuk mendapatkan kuantitas dan kualitas dari feldspar dan lempung, yang siap digunakan sebagai bahan baku sentra keramik serta penyusunan peta tata ruang geologi yang akurat. d. Perlu dibentuk koperasi, yang berfungsi sebagai lembaga dalam penyediaan bahan baku sentra keramik, yang dibina oleh Dinas ESDM setempat, supaya penambangan lempung dan feldspar yang selama ini beroperasi dilakukan dengan kaidah-kaidah yang benar serta tidak adanya tumpang tindih lahan.

\section{UCAPAN TERIMAKASIH}

Ucapan terimakasih disampaikan kepada semua pihak yang telah banyak membantu hingga terlaksananya semua penyelidikan dengan lancar, khususnya kepada Kepala Pusat Sumber Daya Geologi, Badan Geologi.

\section{DAFTAR PUSTAKA}

Anonim., 2012, Kajian Potensi Sumber Daya Geologi untuk Menunjang Ekonomi Kreatif, Pusat Sumber Daya Geologi, Bandung, Tidak dipublikasikan.

Condon,W.H., Pardiyanto, L., Ketner, K.B., Amin, T.C., Gafoer, S., dan Samodra, H., 1996, Peta Geologi Lembar Banjarnegara dan Pekalongan, Jawa, skala 1: 100.000, P3G, Bandung.

Pangestu, M.E., 2008, Pengembangan Industri Kreatif Menuju Visi Ekonomi Kreatif Indonesia 2025; Rencana Pengembangan 14 Subsektor Industri Kreatif Indonesia (2009 - 2015), Departemen Perdagangan Republik Indonesia. 